(с) Коллектив авторов, 2021

Зимина Е.М. ${ }^{1}$, Калошин А.А. ${ }^{1}$, Михайлова Н.А. ${ }^{1}$, Меркушова Е.Д. ${ }^{2}$, Ганковская Л.В. ${ }^{2}$

Влияние соотношения белка и гидроокиси алюминия на проявление протективных свойств рекомбинантного белка слияния OprF-aTox-OprI Pseudomonas aeruginosa и экспрессию генов молекул врожденного иммунитета

\begin{abstract}
${ }^{1}$ Федеральное государственное бюджетное научное учреждение «Научно-исследовательский институт вакцин и сывороток им. И.И. Мечникова» Министерства науки и высшего образования Российской Федерации, 105064, г. Москва, Российская Федерация

${ }^{2}$ Федеральное государственное автономное образовательное учреждение высшего образования «Российский национальный исследовательский медицинский университет имени Н.И. Пирогова» Министерства здравоохранения Российской Федерации, 117997, г. Москва, Российская Федерация
\end{abstract}

\section{Резюме}

Введение. При создании вакцин, в том числе на основе рекомбинантных белков, основным показателем качества препарата является специфическая активность, или иммуногенность. На степень выраженности протективного эффекта влияют содержание в препарате антигена и адъюванта. Подбор оптимального соотношения компонентов является важным этапом при разработке производственной технологии. Влияние соотношения белка и гидроокиси алюминия оценивали по защитным свойствам и по уровню экспрессии генов сенсоров врожденного иммунитета и противомикробного пептида.

Цель исследования - изучить влияние соотношения рекомбинантного белка слияния OprF-aTox-OprI и гидроокиси алюминия на проявление защитных свойств и уровень активности врожденного иммунитета, оцениваемого по экспрессии генов сенсорных рецепторов TLR4, NLRC4 и противомикробного пептида BD2 при иммунизации животных.

Материал и методы. Оценку иммуногенности проводили в модели на мышах при двукратной иммунизации с двухнедельным интервалом и последующим заражением живой вирулентной культурой $P$. aeruginosa. Экспрессию генов оценивали методом полимеразной цепной реакции в реальном времени.

Результаты. Проведена оценка протективных свойств рекомбинантного белка слияния OprF-aTox-OprI в соотношениях с сорбентом $1: 1,1: 2$ и $1: 3$, выявлено влияние иммунизации на экспрессию макрофагами мышей генов Defb2, Tlr4, Nlrc4, Asc и Casp1. При изучении протективных свойств рекомбинантного белка с различными соотношениями белок/сорбент (1: $1,1: 2$ и $1: 3)$ максимальный защитный эффект наблюдали при иммунизации мышей препаратом с соотношением $1: 1$. Введение вакцины влияло на экспрессию макрофагами белков TLR4, BD2, NLRC4, ASC и CASP1 и различалось по степени выраженности ответа врожденного звена иммунной системы в зависимости от рецептуры используемого препарата.

Заключение. Определено оптимальное соотношение рекомбинантного белка слияния OprF-aTox-OprI с сорбентом, соответствующее значению $1: 1$.

Ключевые слова: Pseudomonas aeruginosa; рекомбинантный белок слияния OprF-aTox-OprI; TLR4; дефензины; инфламмасома

Статья получена: 30.10.2020. Принята к печати: 16.01 .2021$.

Для цитирования: Зимина Е.М., Калошин А.А., Михайлова Н.А., Меркушова Е.Д., Ганковская Л.В. Влияние соотношения белка и гидроокиси алюминия на проявление протективных свойств рекомбинантного белка слияния OprF-aTox-OprI Pseudomonas aeruginosa и экспрессию генов молекул врожденного иммунитета. Иммунология. 2021; 42 (1): 29-37. DOI: https://doi.org/10.33029/0206-4952-2021-42-1-29-37

Финансирование. Исследование не имело спонсорской поддержки.
Для корреспонденции Зимина Екатерина Максимовна младший научный сотрудник лаборатории протективных антигенов ФГБНУ НИИВС им. И.И. Мечникова,

Москва, Российская Федерация E-mail: ziminka@yandex.ru https://orcid.org/0000-0003-2167-8905 
Zimina E.M. ${ }^{1}$, Kaloshin A.A. ${ }^{,}$, Mikhailova N.A. ${ }^{1}$, Merkushova E.D. ${ }^{2}$, Gankovskaya L.V. ${ }^{2}$

\title{
The influence of the ratio of protein and aluminum hydroxide on the manifestation of the protective properties of the recombinant fusion protein OprF-aTox-OprI Pseudomonas aeruginosa and the expression of genes of molecules of innate immunity
}

\footnotetext{
${ }^{1}$ I. Mechnikov Research Institute of Vaccines and Sera of the Ministry of Science and Higher Education of the Russian Federation, 105064, Moscow, Russian Federation

${ }^{2}$ N.I. Pirogov Russian National Research Medical University of the Ministry of Health of the Russian Federation, 117997, Moscow, Russian Federation
}

\begin{abstract}
Introduction. The main indicator of the quality of a preparation in the creation vaccines based on recombinant proteins is specific activity or immunogenicity. The severity of the protective effect is influenced by the content of antigen and adjuvant in the preparation. An important step in the development of production technology is the selection of the optimal ratio of components. The effect of the ratio of protein and aluminum hydroxide is assessed by the protective properties and by the level of expression of genes for innate immunity sensors and antimicrobial peptide.

Aim of the study - to investigate the effect of the ratio of protein and aluminum hydroxide on the manifestation of protective properties and the level of activity of innate immunity, assessed by the expression of genes for sensory receptors TLR4, NLRC4 and antimicrobial peptide BD2.

Material and methods. The evaluation of immunogenicity was carried out on a mouse model with two-fold immunization with a two-week interval and subsequent infection with a live virulent $P$. aeruginosa culture. Gene expression was assessed by real-time PCR.

Results. The assessment of the protective properties of the recombinant fusion protein OprF-aTox-OprI in ratios with the sorbent $1: 1,1: 2$ and $1: 3$ was carried out, the effect of immunization on the expression of Defb2, Tlr4, Nlrc4, Asc and Casp1 genes by murine macrophages was revealed. During the research the protective properties of a recombinant protein with different protein-sorbent ratios $(1: 1,1: 2$, and $1: 3)$, the maximum protective effect was observed when mice were immunized with a preparation with a $1: 1$ ratio. The injecting of the vaccine affected the expression of proteins TLR4, BD2, NLRC4, ASC and CASP1 by macrophages and differed in the severity of the response of the innate immune system depending on the formulation of the preparation used.

Conclusion. As a result of the work performed, the optimal ratio of the fusion recombinant protein OprF-aTox-OprI with the sorbent was determined, corresponding to a value of $1: 1$ and confirmed by the results of immunological studies.
\end{abstract}

Keywords: Pseudomonas aeruginosa; fusion recombinant protein OprF-aTox-OprI; TLR4; defensins; inflammasome

Received: 30.10 .2020 . Accepted: 16.01 .2021 .

For citation: Zimina E.M., Kaloshin A.A., Mikhailova N.A., Merkushova E.D., Gankovskaya L.V. The influence of the ratio of protein and aluminum hydroxide on the manifestation of the protective properties of the recombinant fusion protein OprF-aTox-OprI Pseudomonas aeruginosa and the expression of genes of molecules of innate immunity. Immunologiya. 2021; 42 (1): 29-37. DOI: https://doi.org/10.33029/0206-4952-2021-42-1-29-37 (in Russian)

Funding. The study had no sponsor support.

Conflict of interests. The authors declare no conflict of interests.

\section{Введение}

Ввиду малой эффективности антибактериальных лекарственных средств, применяемых для лечения гнойновоспалительных заболеваний, вызываемых синегнойной палочкой (Pseudomonas aeruginosa), более 100 лет предпринимаются исследования по созданию иммуно-

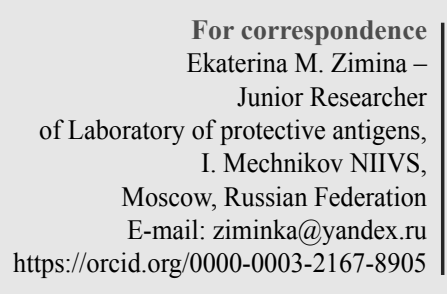

For correspondence terina M. Zimina protective antigens, I. Mechnikov NIIVS, Moscow, Russian Federation E-mail: ziminka@yandex.ru https://orcid.org/0000-0003-2167-8905 профилактических вакцин. Полученные классическими методами варианты, обладая удовлетворительной иммуногенностью, но содержащие примеси бактериального липополисахарида, оказывались реактогенными, что препятствовало их применению в клинической практике. С развитием биотехнологии и генной инженерии появи- 
лось новое направление в разработке препаратов - вакцин на основе рекомбинантных протективных антигенов. Многие экспериментальные антисинегнойные вакцины в настоящее время тестируются в доклинических и клинических испытаниях $[1,2]$. Перспективными оказались препараты, при создании которых использовались нетоксичные и иммуногенные антигены $P$. aeruginosa. Использование генно-инженерных методов позволяет создавать универсальные и безопасные технологии получения протективных рекомбинантных белков.

На основе результатов многолетних исследований иммунобиологических свойств ряда рекомбинантных белков P. aeruginosa, проведенных в ФГБНУ НИИВС им. И.И. Мечникова, получены варианты, среди которых наибольший интерес для последующего исследования представляет белок слияния OprF-aTox-OprI [3].

Известно, что для усиления иммуногенных свойств рекомбинантных белков используют различные адъюванты [4]. С этой целью в состав вакцин включают гель гидроокиси алюминия, который является сорбентом и обеспечивает продолжительность презентации антигенов для клеток иммунной системы. Эффективность протективного действия зависит от условий сорбции и соотношения белок/сорбент.

На доступность эпитопов влияют конформационные изменения антигена, которые могут наступить в процессе его получения (наработка материала в неродственном штамме-продуценте, очистка рекомбинантного продукта). При разработке вакцин на основе рекомбинантных белков важно учитывать нативность белка и технологичность процесса сорбции. Оптимальное соотношение компонентов в препарате способно существенно усилить иммуногенность. Находящиеся в доступном состоянии эпитопы быстрее распознаются клетками иммунной системы, в результате чего запускается каскад реакций, направленных на защиту организма.

Подтверждением эффективности выбранного в качестве оптимального соотношения белок/сорбент могут служить данные по выживаемости животных (при использовании модели на мышах и экспериментального заражения) и по экспрессии генов, определяющих факторы развития врожденного иммунитета.

\section{Материал и методы}

Экспериментальные иммуногены. При выполнении работы использовали полученный в лаборатории протективных антигенов ФГБНУ НИИВС им. И.И. Мечникова рекомбинантный белок слияния OprF-aTox-OprI, сорбированный в разных дозах (50, 75 и 100 мкг белка) на геле гидроокиси алюминия в соотношениях $1: 1$, $1: 2$ и $1: 3$, и прошедшую доклинические исследования рекомбинантную вакцину синегнойную (РВС), которая представляет собой комплекс рекомбинантных белков OprF и анатоксина P. aeruginosa, сорбированных на геле гидроокиси алюминия [2].

Экспериментальные животные. В экспериментах использовали самок белых беспородных мышей весом 16-18 г, полученных из филиала «Андреевка» ФГБУН
НЦБМТ ФМБА России. Животных содержали в виварии ФГБНУ НИИВС им. И.И. Мечникова. Уход за животными осуществляли в соответствии с ГОСТом 33216-2014 («Правила содержания и ухода за лабораторными грызунами и кроликами») и Федеральным законом РФ «Об ответственном обращении с животными» (№ 498-Ф3 от 27.12.2018).

Оценка протективных свойств. Самок белых беспородных мышей весом 16-18 г иммунизировали двукратно с двухнедельным интервалом внутрибрюшинно. Экспериментальное инфицирование животных проводили внутрибрюшинно различными дозами живой вирулентной культуры $P$. aeruginosa штамма $P A-103$ в объеме 0,5 мл. Дозы заражения готовили путем разведения смытой изотоническим раствором хлорида натрия с агаризованной среды Мюллер-Хинтона (Amresco, США) культуры, используя стандарт мутности («Ормет», Россия) и спектрофотометр Genesys 6 (Thermo scientific, США). ЛД фикации Ашмарина-Воробьева [5]. Индекс эффективности (ИЭ) определяли как отношение ЛД ${ }_{50}$ опытной и контрольной групп.

Выделение перитонеальных макрофагов. Взятие перитонеального экссудата проводили после курса иммунизаций за сутки до заражения, на 2-е и 5-е сутки после заражения индивидуально у нескольких мышей в каждой группе по общепринятой практике [6].

Определение уровня экспрессии генов. Клеточную суспензию, содержащую макрофаги, помещали в лизирующий раствор из коммерческого набора «РИБО-сорб» («Интерлабсервис», Россия) и выделяли РНК согласно инструкции. При постановке полимеразной цепной реакции в реальном времени (ПЦР-РВ) использовали наборы реагентов «ОТ-1» для обратной транскрипции («Синтол», Россия) и «ПЦР-Микс» («Синтол», Россия), и следующие пары праймеров:

Tlr4 - AGCTTCTCCAATTTTTCAGAACTTC,

TGAGAGGTGGTGTAAGCCATGC;

Defb2 - CTGCTGCTGATATGCTGCCTC,

TAAACTTCCAACAGCTGGAGTGG;

Nlrc4 - GTGTTTGCAGCACTTGGACCTC,

CTGGTGAAAGGTTACAGGCTGC;

Casp1 - GGCACATTTCCAGGACTGACTG,

GCAAGACGTGTACGAGTGGTTG;

Asc - AGGAGATCCAGCAGACGTGTGA,

ATGCCTGCCATCTCGACTTCCA

Экспрессию целевого гена рассчитывали относительно гена домашнего хозяйства $A c t b$, кодирующего $\beta$-актин, по методу « $\Delta \Delta \mathrm{Ct} »[7]$. Для сравнения экспрессии целевого гена у животных внутри одной группы в разные дни после иммунизации был применен критерий Вилкоксона. При сравнении уровней экспрессии генов между разными группами экспериментальных животных использовался непараметрический $U$-критерий Манна-Уитни.

\section{Результаты}

На первом этапе было сформировано четыре группы по 50 животных. Животным 1-й и 2-й групп двукратно 
Таблица 1. Результаты оценки иммуногенности рекомбинантного белка слияния OprF-aTox-OprI при соотношении белок/ сорбент $1: 3$ в сравнении с вакциной РВС

\begin{tabular}{|c|c|c|c|c|}
\hline Препарат & $\begin{array}{c}\text { Доза зара- } \\
\text { жения, млн } \\
\text { микробных } \\
\text { клеток } \\
\text { (м.кл.) } \\
\end{array}$ & $\begin{array}{c}\text { Коли- } \\
\text { чество } \\
\text { павших/ } \\
\text { выживших } \\
\text { животных }\end{array}$ & $\begin{array}{c}\text { ЛД } \\
\text { мл, } \\
\text { м.кл. }\end{array}$ & ИЭ \\
\hline \multirow{5}{*}{$\begin{array}{l}\text { OprF-aTox- } \\
\text { OprI, } \\
50 \text { мкг }\end{array}$} & 200 & $6 / 4$ & \multirow{5}{*}{40,61} & \multirow{5}{*}{1} \\
\hline & 100 & $3 / 7$ & & \\
\hline & 50 & $2 / 8$ & & \\
\hline & 25 & $4 / 6$ & & \\
\hline & 12,5 & $2 / 8$ & & \\
\hline \multirow{5}{*}{$\begin{array}{l}\text { OprF-aTox- } \\
\text { OprI, } \\
75 \text { мкг }\end{array}$} & 200 & $9 / 1$ & \multirow{5}{*}{40,61} & \multirow{5}{*}{1} \\
\hline & 100 & $7 / 3$ & & \\
\hline & 50 & $4 / 6$ & & \\
\hline & 25 & $3 / 7$ & & \\
\hline & 12,5 & $4 / 6$ & & \\
\hline \multirow{5}{*}{ PBC } & 200 & $10 / 0$ & \multirow{5}{*}{87,05} & \multirow{5}{*}{2,14} \\
\hline & 100 & $5 / 5$ & & \\
\hline & 50 & $1 / 9$ & & \\
\hline & 25 & $2 / 8$ & & \\
\hline & 12,5 & $0 / 10$ & & \\
\hline \multirow{5}{*}{$\begin{array}{l}\text { Контроль } \\
\text { (неиммуни- } \\
\text { зированные } \\
\text { животные) }\end{array}$} & 100 & $9 / 1$ & \multirow{5}{*}{40,61} & \multirow{5}{*}{ - } \\
\hline & 50 & $7 / 3$ & & \\
\hline & 25 & $6 / 4$ & & \\
\hline & 12,5 & $4 / 6$ & & \\
\hline & 6,25 & $1 / 9$ & & \\
\hline
\end{tabular}

Примечание. РВС - рекомбинантная вакиина синегнойная; ИЭ-индекс эффективности.

с двухнедельным интервалом вводили рекомбинантный белок слияния OprF-aTox-OprI в соотношении белок/сорбент $1: 3$ в иммунизирующих дозах 50 и 75 мкг белка, соответственно. 3-й группе по той же схеме вводили препарат сравнения - рекомбинантную вакцину синегнойную (РВC). 4-я группа была представлена неиммунизированными животными. После окончания курса иммунизаций животным вводили живую вирулентную культуру P. aeruginosa штамма $P A-103$ в дозах от 200 до 12,5 миллионов микробных клеток (млн м.кл.) для опытных групп и от 100 до 6,25 млн м.к. для контрольных животных. В течение 7 дней в группах вели учет павших животных и на основании этих данных рассчитывали ЛД ${ }_{50}$ и ИЭ, как описано в разделе «Материал и методы».

Апробированное соотношение белок/сорбент $1: 3$ обеспечивало максимальный защитный эффект при введении РВС, однако в случае с гибридным белком применение соотношения $1: 3$ привело к снижению протективной активности независимо от иммунизирующей дозы по сравнению с вакцинацией РВС (табл. 1).

При подборе оптимального содержания сорбента по отношению к белку были апробированы два варианта соотношения (1:1 и $1: 2)$ и расширен диапазон иммунизирующих доз. Количество групп было увеличено до 7. Первым 3 группам двукратно с двухнедельным интервалом вводили рекомбинантный белок слияния OprF-aTox-OprI в соотношении белок/сорбент $1: 1$ в иммунизирующих дозах 50, 75 и 100 мкг белка соответственно. 4-й, 5-й и 6-й группам по той же схеме вводили рекомбинантный белок слияния OprF-aToxOprI в соотношении белок/сорбент $1: 2$ в иммунизирующих дозах 50, 75 и 100 мкг белка. 7-я группа была представлена неиммунизированными животными. Последующее заражение живой вирулентной культурой P. aeruginosa штамма $P A-103$ и расчет ЛД ${ }_{50}$ и ИЭ проводили аналогично первому опыту.

Как видно из табл. 2, максимальный защитный эффект выявлен при соотношении белок/сорбент $1: 1$ в иммунизирующей дозе 50 мкг белка (ИЭ - 4,3). А при соотношении белок/сорбент $1: 2$ проявлялся дозозависимый эффект.

Эффективность вышеуказанных соотношений белок/сорбент (выживаемость зараженных иммунизированных животных) подтверждена исследованиями по оценке уровня экспрессии генов сенсорных рецепторов врожденного иммунитета, таких как TLR4 и NLRC4, и противомикробного пептида BD2.

У животных собирали макрофаги за сутки до заражения, на 2-е и 5-е сутки после заражения и выполняли ПЦР, как указано в разделе «Материал и методы». Определяли экспрессию генов Defb2, Tlr4, Nlrc4, Asc и Casp1 в группах здоровых незараженных и неиммунизированных мышей, группах неиммунизированных мышей и группах иммунизированных и зараженных мышей. Полученные данные сравнивали с показателями у мышей, иммунизированных рекомбинантным белком слияния OprF-aTox-OprI в соотношениях белок/ сорбент $1: 1$ и $1: 2$, и у зараженных мышей (контроль). Количество мРНК выражали в относительных единицах.

У мышей, иммунизированных рекомбинантным белком в соотношениях $1: 1$ и $1: 2$, не выявлено достоверных различий в уровне экспрессии гена Tlr4, а по сравнению со здоровыми неиммунизированными животными выявлена тенденденция к увеличению экспрессии гена Tlr4.

После заражения мышей $P$. aeruginosa на 2-е и 5-е сутки повторно определяли уровень экспрессии гена $T l r 4$. Пик увеличения экспрессии у иммунизированных животных приходился на 2-е сутки, тогда как на 5-е сутки экспрессия Tlr4 снижалась до показателей перед заражением. У животных контрольной группы (неиммунизированных) возрастание экспрессии гена Tlr4 начиналось к 5-м суткам после инфицирования.

При сравнении экспрессии гена Tlr4 у здоровых, контрольных и иммунизированных мышей на 2-е сутки после инфицирования показано, что в группе животных, иммунизированных белком OprF-aTox-OprI в соотношении с сорбентом $1: 1$, наблюдался самый высокий уровень экспрессии целевого гена: в 24 раза выше, чем у контрольных мышей $(p=0,049)$; в 8 раз выше, чем у здоровых мышей $(p=0,049)$, и в 3 раза выше, чем у мышей, иммунизированных препаратом с соотношением белок/сорбент $1: 2$ (рис. 1).

Достоверных различий уровня экспрессии гена противомикробного пептида $\beta$-дефензина BD2 у мышей, 
иммунизированных рекомбинантным белком OprF-aToxOprI в соотношениях с сорбентом $1: 1$ и $1: 2$, не выявлено, а по сравнению со здоровыми животными имелась тенденция к увеличению экспрессии гена Defb2.

При сравнении экспрессии гена Defb2 на 2-е сутки после инфицирования показано, что у животных, иммунизированных препаратом с соотношением белок/сорбент $1: 2$, уровень экспрессии был значительно выше, чем у остальных групп мышей:

- в 14 раз больше, чем у здоровых животных $(p=0,04)$

- в 11 раз по отношению к группе мышей, иммунизированных препаратом с соотношением $1: 1$ $(p=0,04)$

- в 24 раза больше по сравнению с инфицированными животными.

Экспрессия гена Defb2 у животных, получавших препарат, содержащий рекомбинантный белок OprF-aToxOprI в соотношении с сорбентом $1: 1$, была сопоставима с таковой у здоровых и контрольных животных (рис. 2).

Была также изучена экспрессия генов инфламмасомного комплекса Nlrc4, Asc и Caspl у здоровых и иммунизированных животных в динамике.

Достоверных различий уровня экспрессии генов инфламмасомного комплекса у животных, которым вводили рекомбинантный белок OprF-aTox-OprI в coотношениях с сорбентом $1: 1$ и $1: 2$, не выявлено, однако по сравнению со здоровыми животными имелась тенденция к увеличению экспрессии генов Nlrc4, Asc и Caspl.

Показано, что у всех иммунизированных животных после заражения $P$. aeruginosa наблюдалось усиление экспрессии генов Nlrc4, Asc и Casp1 на 2-е сутки. На 5-е сутки уровень экспрессии генов снижался у животных, получавших вариант в соотношении с сорбентом $1: 2$, и возрастал либо оставался неизменным у мышей, иммунизированных OprF-aTox-OprI 1 : 1, тогда как у контрольных мышей максимум экспрессии наблюдался к 5-м суткам.

Сравнение уровней экспрессии генов Nlrc4, Asc и Casp1 у здоровых, контрольных и иммунизированных белком OprF-aTox-OprI в соотношениях с сорбентом $1: 2$ и $1: 1$ мышей на 2-е сутки после инфицирования $P$. aeruginosa показало, что у животных, вакцинированных препаратом с соотношением с сорбентом 1 : 2, уровень экспрессии гена Nlrc4 был значительно выше, чем у остальных групп мышей. Статистически достоверное повышение выявлено между иммунизированными животными, экспрессия Nlrc4 оказалась в 5 раз выше в группе с соотношением белок/сорбент $1: 1(p=0,04)$ (рис. 3).

У мышей, иммунизированных вариантом препарата с соотношением $1: 1$, уровень экспрессии генов Asc и Casp1 был выше, чем у животных остальных групп (рис. 4, 5).

\section{Обсуждение}

Ранее при разработке вакцины РВС для сорбции выбрано соотношение белок/сорбент 1 : 3, обеспечиваю-
Таблица 2. Результаты оценки иммуногенности рекомбинантного белка слияния OprF-aTox-OprI в вариантах соотношения белок/сорбент $1: 1$ и $1: 2$

\begin{tabular}{|c|c|c|c|c|c|}
\hline \multicolumn{2}{|c|}{ Препарат } & $\begin{array}{c}\text { Доза } \\
\text { зара- } \\
\text { жения, } \\
\text { млн } \\
\text { м.кл. }\end{array}$ & $\begin{array}{c}\text { Коли- } \\
\text { чество } \\
\text { павших/ } \\
\text { выживших } \\
\text { животных }\end{array}$ & $\begin{array}{c}\text { ЛД }_{50}, \\
\text { млн } \\
\text { м.кл. }\end{array}$ & ИЭ \\
\hline \multirow{5}{*}{ 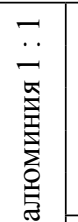 } & \multirow{5}{*}{$\begin{array}{l}\text { OprF- } \\
\text { aTox- } \\
\text { OprI, } \\
50 \text { мкг }\end{array}$} & 200 & $4 / 6$ & \multirow{5}{*}{107,18} & \multirow{5}{*}{4,3} \\
\hline & & 100 & $3 / 7$ & & \\
\hline & & 50 & $3 / 7$ & & \\
\hline & & 25 & $4 / 6$ & & \\
\hline & & 12,5 & $0 / 10$ & & \\
\hline \multirow{5}{*}{\multicolumn{2}{|c|}{ 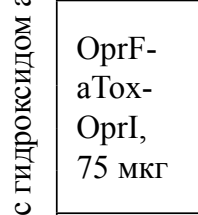 }} & 200 & $9 / 1$ & \multirow{5}{*}{46,65} & \multirow{5}{*}{1,9} \\
\hline & & 100 & $9 / 1$ & & \\
\hline & & 50 & $5 / 5$ & & \\
\hline & & 25 & $2 / 8$ & & \\
\hline & & 12,5 & $1 / 9$ & & \\
\hline \multirow{5}{*}{ 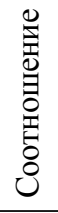 } & \multirow{5}{*}{$\begin{array}{l}\text { OprF- } \\
\text { aTox- } \\
\text { OprI, } \\
100 \text { мкг }\end{array}$} & 200 & $7 / 3$ & \multirow{5}{*}{65,98} & \multirow{5}{*}{2,6} \\
\hline & & 100 & $6 / 4$ & & \\
\hline & & 50 & $5 / 5$ & & \\
\hline & & 25 & $2 / 8$ & & \\
\hline & & 12,5 & $1 / 9$ & & \\
\hline \multirow{5}{*}{ 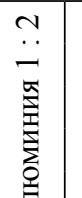 } & \multirow{5}{*}{$\begin{array}{l}\text { OprF- } \\
\text { aTox- } \\
\text { OprI, } \\
50 \text { мкг }\end{array}$} & 200 & $10 / 0$ & \multirow{5}{*}{57,44} & \multirow{5}{*}{2,3} \\
\hline & & 100 & $6 / 4$ & & \\
\hline & & 50 & $3 / 7$ & & \\
\hline & & 25 & $3 / 7$ & & \\
\hline & & 12,5 & $1 / 9$ & & \\
\hline \multirow{5}{*}{\multicolumn{2}{|c|}{ 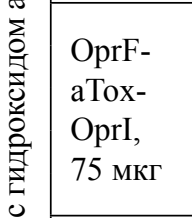 }} & 200 & $8 / 2$ & \multirow{5}{*}{61,56} & \multirow{5}{*}{2,5} \\
\hline & & 100 & $7 / 3$ & & \\
\hline & & 50 & $5 / 5$ & & \\
\hline & & 25 & $2 / 8$ & & \\
\hline & & 12,5 & $0 / 10$ & & \\
\hline \multirow{5}{*}{ 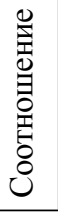 } & \multirow{5}{*}{$\begin{array}{l}\text { OprF- } \\
\text { aTox- } \\
\text { OprI, } \\
100 \text { мкг }\end{array}$} & 200 & $7 / 3$ & \multirow{5}{*}{87,06} & \multirow{5}{*}{3,5} \\
\hline & & 100 & $6 / 4$ & & \\
\hline & & 50 & $3 / 7$ & & \\
\hline & & 25 & $0 / 10$ & & \\
\hline & & 12,5 & $1 / 9$ & & \\
\hline \multirow{5}{*}{\multicolumn{2}{|c|}{$\begin{array}{l}\text { Контроль } \\
\text { (неиммуни- } \\
\text { зированные } \\
\text { животные) }\end{array}$}} & 100 & $10 / 0$ & \multirow[t]{5}{*}{25} & \multirow[t]{5}{*}{-} \\
\hline & & 50 & $9 / 1$ & & \\
\hline & & 25 & $5 / 5$ & & \\
\hline & & 12,5 & $1 / 9$ & & \\
\hline & & 6,25 & $0 / 10$ & & \\
\hline
\end{tabular}

Примечание. ИЭ-индекс эффективности.

щее максимальный защитный эффект (ИЭ 3,0-3,3) [2]. По аналогии проведена сорбция рекомбинантного белка слияния OprF-aTox-OprI в двух дозах (50 и 75 мкг) на гидроксид алюминия. Иммунизирующая доза, соответствующая 50 мкг белка, выбрана по результатам предшествующих исследований протективной активности рекомбинантного белка слияния, а доза 75 мкг соответствовала содержанию антигенов в одной дозе рекомбинантной вакцины РВС. Для сравнения защитного эффекта сорбированных препаратов в исследовании использовали серию вакцины РВС. 


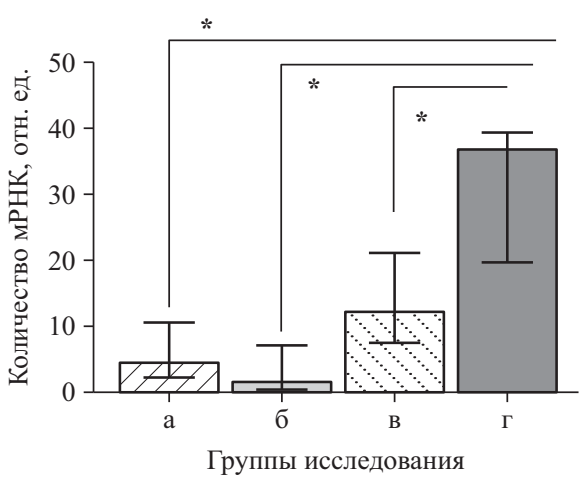

Рис. 1. Экспрессия гена Tlr4 макрофагами здоровых (а), контрольных (б) и иммунизированных мышей рекомбинантным белком слияния OprF-aTox-OprI в соотношениях с сорбентом $1: 2$ (в) и $1: 1$ (г) на 2-е сутки после инфицирования P. aeruginosa

Здесь и на рис. 2-5: экспрессию иелевых генов нормализовали на ген домашнего хозяйства Actb.

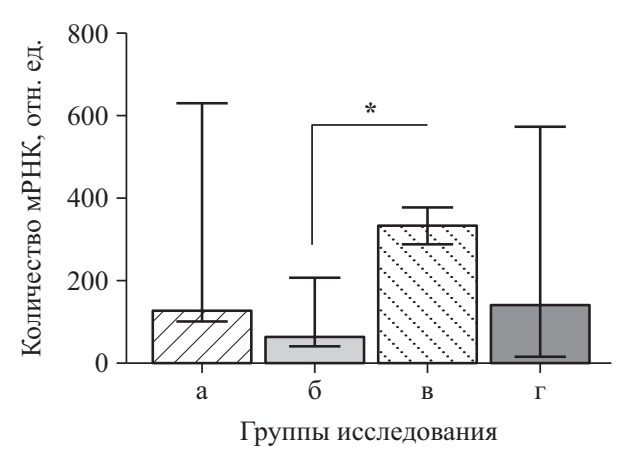

Рис. 3. Экспрессия гена Nlrc4 макрофагами здоровых (а), контрольных (б) и иммунизированных рекомбинантным белком слияния OprF-aTox-OprI в соотношениях с сорбентом $1: 2$ (в) и $1: 1$ (г) мышей на 2-е сутки после инфицирования P. aeruginosa

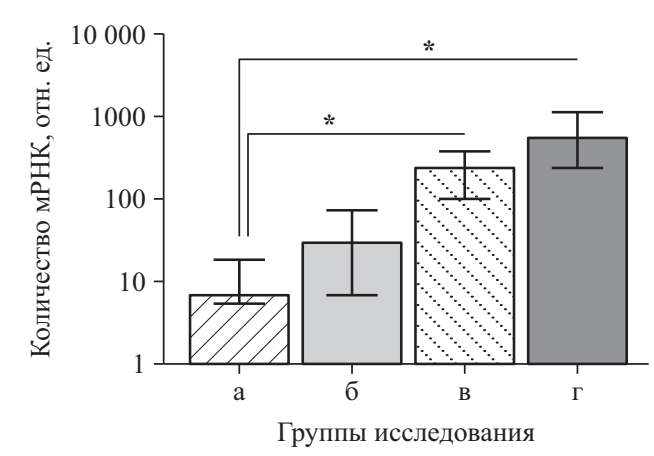

Рис. 4. Экспрессия гена $A s c$ макрофагами здоровых (а), контрольных (б) и иммунизированных рекомбинантным белком слияния OprF-aTox-OprI в соотношениях с сорбентом $1: 2$ (в) и $1: 1$ (г) мышей на 2-е сутки после инфицирования P. aeruginosa

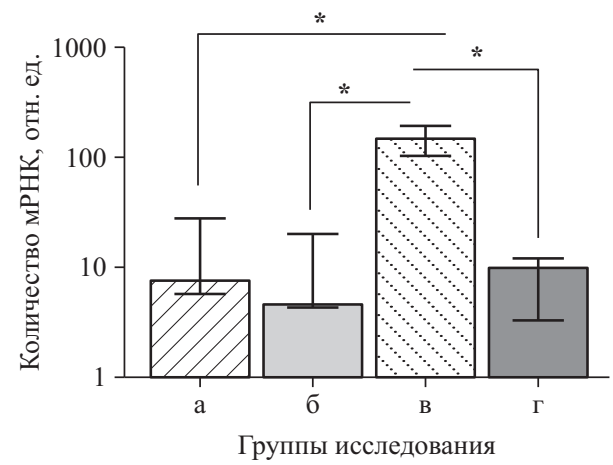

Рис. 2. Экспрессия гена Defb2 макрофагами здоровых (a), контрольных (б) и иммунизированных мышей рекомбинантным белком слияния OprF-aTox-OprI в соотношениях с сорбентом $1: 2$ (в) и $1: 1$ (г) на 2-е сутки после инфицирования P. aeruginosa

Используемое при сорбции рекомбинантного белка слияния OprF-aTox-OprI соотношение белок/сорбент, равное $1: 3$, привело к снижению протективной активности вне зависимости от иммунизирующей дозы (табл. 1). Снижение протективной активности при увеличении содержания сорбента, возможно, происходило из-за прочного связывания белка с сорбентом, которое препятствует взаимодействию антигенов с клетками иммунной системы. Уменьшение содержания сорбента и расширение диапазона иммунизирующих доз (50, 75 и 100 мкг белка в одной дозе) свидетельствовали о важности оптимизации соотношения белок/сорбент. Иммунизирующая доза 50 мкг белка при соотношении с сорбентом $1: 1$ обеспечивала максимальный защитный эффект (ИЭ - 4,3). Дозозависимый эффект прослеживали при иммунизации препаратом с соотношением белок/сорбент $1: 2$. При иммунизирующей дозе 50 мкг белка ИЭ соответствовал 2,3 и увеличился до 3,5 при введении препарата в дозе 100 мкг белка, что, по-видимому, связано с большей доступностью анти-

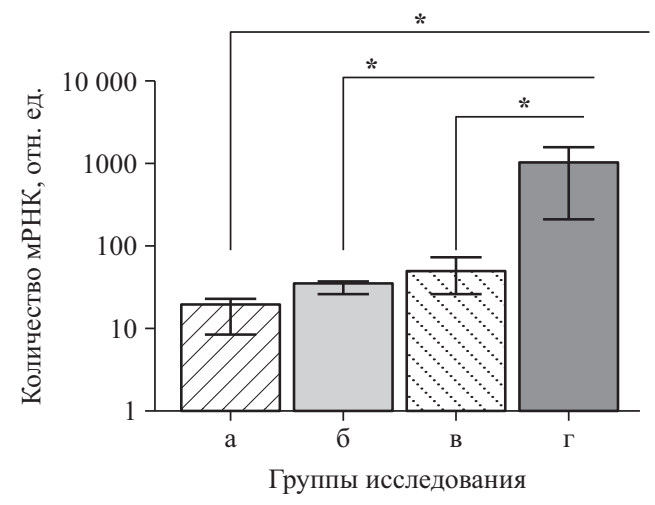

Рис. 5. Экспрессия Caspl макрофагами здоровых (а), контрольных (б) и иммунизированных рекомбинантным белком слияния OprF-aTox-OprI в соотношениях с сорбентом $1: 2$ (в) и $1: 1$ (г) мышей на 2-е сутки после инфицирования P. aeruginosa 
гена для клеток иммунной системы. По нашему мнению, для дальнейшего изучения рекомбинантного белка слияния как кандидатной синегнойной вакцины соотношение белок/сорбент $1: 1$ представляется наиболее перспективным, потому что максимальный протективный эффект достигается при минимальной концентрации белка, а содержание сорбента не превышает значений, допустимых при производстве вакцин.

Результаты оценки защитных свойств рекомбинантного белка OprF-aTox-OprI в вариантах сорбции $1: 1$ и $1: 2$ подтверждены исследованием экспрессии генов противомикробного пептида и ключевых сенсоров врожденного иммунитета.

У иммунизированных мышей активация врожденного звена иммунитета и распознавание антигена происходили раньше, чем в контрольной группе (неиммунизированных инфицированных животных). Ранее это было показано для рекомбинантного анатоксина, который активировал экспрессию TLR2, TLR4 и TLR9, стимулировал продукцию провоспалительных и противовоспалительных цитокинов [8].

После курса иммунизаций у животных опытных групп не выявлено достоверных различий в уровне экспрессии гена Tlr4, но имелась тенденция к увеличению экспрессии по сравнению с группой здоровых неиммунизированных незараженных мышей. Влияние иммунизации как средства подготовки организма подтверждается данными по изучению уровня экспрессии Tlr4 на 2-е сутки после заражения. При введении животным рекомбинантного белка слияния OprF-aTox-OprI в варианте сорбции $1: 1$ он оказался в 24 раза выше, чем в контрольной группе, и в 3 раза, чем при иммунизации соотношением $1: 2$. Эти результаты согласуются с исследованиями, в которых показано, что TLR4 имеет решающее значение в устойчивости организма к P. aeruginosa, так как его дефицит приводит к усилению продукции провоспалительных цитокинов и снижению продукции iNOs и BD2 $[9,10]$.

Данные, полученные при изучении экспрессии гена $D e f b 2$, неодназначны. При изначальном более высоком уровне экспрессии у мышей, иммунизированных препаратом с соотношением белок/сорбент $1: 1$, на 2-е сутки после заражения пик экспрессии наблюдался в группе с вариантом препарата белок/сорбент $1: 2$ : в 14 раз выше по сравнению со здоровыми животными $(p=0,04)$, в 11 раз - по сравнению с группой, получившей другой вариант препарата $(p=0,04)$, и в 24 раза - по сравнению с инфицированными животными.

Дефензины играют важную роль как во врожденном, так и в адаптивном иммунитете благодаря своим антимикробным, регуляторным и хемотаксическим эффектам. BD2 способствует клиренсу P. aeruginosa путем ингибирования макрофагов через понижающую регуляцию EGR1 и c-FOS, а исследования in vivo продемонстрировали индивидуальные и комбинированные эффекты BD2 и $\mathrm{BD} 3$, регулирующие бактериальную нагрузку и продукцию ИФН- $\gamma$, MІР-2, ИЛ-1 $\beta$, ФНО $\alpha$, индуцибельной NO-синтазы (iNOS), TLR2, TLR4, MyD88 и NF-кB [11]. B наших экспериментах бактериальная нагрузка увели- чивалась на 5-е сутки после инфицирования путем нокдауна $D e f b 2$ или $D e f b 3$, что свидетельствовало о важной роли дефензинов в клиренсе $P$. aeruginosa [12].

Данные по уровню экспрессии генов инфламмасомного комплекса также неоднозначны. NLRC4, относящийся к семейству NOD-подобных рецепторов (NLR), рассматривается как необходимый сенсорный комплекс, запускающий активацию врожденного иммунитета $[13,14]$. Известно, что за активацией и олигомеризацией рецепторов NLR следует рекрутирование, кластеризация и аутоактивация каспазы через белковый адаптер ASC [15]. Активация CASP1 опосредует процессинг и секрецию провоспалительных цитокинов, таких как ИЛ-1 $\beta$ и ИЛ-18 [16].

Грам-отрицательные бактерии, в частности $P$. aeruginosa, запускают активацию инфламмасомы NLRC4, обеспечивая более эффективную элиминацию патогена $[17,18]$. Данные, полученные ходе настоящей работы, свидетельствуют об увеличении экспрессии всех компонентов инфламмасомного комплекса (NLRC4, ASC, CASP1) у иммунизированных мышей ко 2-м суткам, тогда как у контрольных (неиммунизированных инфицированных) животных усиление экспрессии наблюдалось позднее. Это указывает на более раннее распознавание патогена и эффективный ответ иммунной системы на введение $P$. aeruginosa. Необходимо отметить, что в целом динамика экспрессии генов Nlrc4, Asc, Caspl совпадала у мышей, иммунизированных рекомбинантным белком OprF-aTox-OprI в соотношениях с сорбентом $1: 1$ и $1: 2$, однако более выраженные изменения наблюдались при использовании препарата с соотношением белок/адъювант $1: 1$.

Полученные результаты согласуются с данными, касающимися титров специфических антител к отдельным компонентам рекомбинантного белка слияния OprF-aToxOprI в сыворотке иммунизированных мышей [19], поскольку известно, что активация врожденного иммунитета является необходимым условием для развития адаптивного иммунитета, как клеточного, так и гуморального.

\section{Заключение}

По результатам проведенной работы выявлено влияние содержания сорбента в препарате на проявление защитных свойств и активацию экспрессии генов противомикробного пептида и ключевых сенсоров врожденного иммунитета. Из полученных результатов следует, что соотношение белка и гидроксида алюминия $1: 1$ и иммунизирующая доза 50 мкг белка для рекомбинантного белка слияния OprF-aTox-OprI P. aeruginosa эффективны в активации экспрессии генов Tlr4, Nlrc4, $D e f b 2$ и обладают большей протективной активностью.

\section{Вклад авторов}

Сбор и обработка материала - Зимина Е.М., Калошин А.А., Меркушова Е.Д.; статистическая обработка Зимина Е.М., Меркушова Е.Д.; написание текста - Зимина Е.М.; редактирование - Михайлова Н.А., Ганковская Л.В. 


\section{- Литература}

1. Rello J., Krenn C.G., Locker G., Pilger E., Madl C. et al A randomized placebo-controlled phase II study of a Pseudomonas vaccine in ventilated ICU patients. Crit. Care. 2017; 21 (1): 22 DOI: https://www.doi.org/10.1186/s13054-017-1601-9.

2. Михайлова Н.А., Калошин А.А., Зимина Е.М., Солдатенкова А.В., Поддубиков А.В. Доклинические исследования рекомбинантной вакцины синегнойной. Журнал микробиологии, эпидемиологии и иммунобиологии. 2018; 6: 31-7. DOI: https://www. doi.org/10.36233/0372-9311-2018-6-31-37.

3. Калошин А.А., Солдатенкова А.В., Зимина Е.М., Михайлова Н.А. Получение слитых рекомбинантных белков OprF- $\Delta \mathrm{OprI}$ $\Delta \mathrm{OprF}-\Delta \mathrm{Oprl}$ и OprF-aTox- $\Delta$ Oprl Pseudomonas aeruginosa. Журнал микробиологии, эпидемиологии и иммунобиологии. 2017; 5 32-8. DOI: https:/www.doi.org/10.36233/0372-9311-2017-5-32-38.

4. Хаитов Р.М. Иммуномодуляторы: мифы и реальность. Иммунология. 2020; 41 (2): 101-6. DOI: https://www.doi. org/10.33029/0206-4952-2020-41-2-101-106.

5. Ашмарин И.П., Воробьев А.А. Статистические методы в микробиологических исследованиях. Ленинград : Медгиз, 1962: 180 с.

6. Ковальчук Л.В. (ред.), Игнатьева Г.А. (ред.), Ганковская Л.В. (ред.) Иммунология. Практикум. Учебное пособие. Москва : «Гэотар-Медицина», 2015: 176 с.

7. Ребриков Д.В. (ред.), Саматов Г.А., Трофимов Д.Ю., Семенов П.А., Савилова А.М., Кофиади И.А., Абрамов Д.Д. ПЦР «в реальном времени». Москва : БИНОМ. Лаборатория знаний, 2000: 223 c

8. Солдатенкова А.В., Ахматова Н.К., Михайлова Н.А. Влияние рекомбинантного анатоксина на эффекторы иммунного ответа у мышей. Иммунология. 2012; 33 (5): 245-9.

9. Huang X., Du W., McClellan S.A., Barrett R.P., Hazlett L.D. TLR4 is required for host resistance in Pseudomonas aeruginosa keratitis. Invest. Ophthalmol. Vis. Sci. 2006; 47 (11): 4910-6. DOI: https://www.doi.org/10.1167/iovs.06-0537.

10. Awasthi S., Singh B., Ramani V., Xie J., Kosanke S. TLR4 interacting SPA4 peptide improves host defense and alleviates tissue injury in a mouse model of Pseudomonas aeruginosa lung infection.
PLoS One. 2019; 14 (1). Published 2019 Jan 28. DOI: https://www doi.org/10.1371/journal.pone.0210979.

11. Wu Y., Li D., Wang Y., Liu X., Zhang Y. et al. Beta-Defensin 2 and 3 Promote Bacterial Clearance of Pseudomonas aeruginosa by Inhibiting Macrophage Autophagy through Downregulation of Early Growth Response Gene-1 and c-FOS. Front. Immunol. 2018, 9: 211. Published 2018 Feb 13. DOI: https://www.doi.org/10.3389/ fimmu.2018.00211.

12. Wu M., McClellan S.A., Barrett R.P., Zhang Y., Hazlett L.D. Beta-defensins 2 and 3 together promote resistance to Pseudomonas aeruginosa keratitis. J. Immunol. 2009; 183 (12): 8054-60. DOI: https://www.doi.org/10.4049/jimmunol.0902140.

13. Пирожков С.В., Литвицкий П.Ф. Инфламмасомные болезни. Иммунология. 2018; 39 (2-3): 158-65. DOI: https://www.doi org/10.18821/0206-4952-2018-39-2-3-158-165.

14. Chen K.W., Grob C.J., Sotomayor F.V., Stacey K.J., Tschopp J. et al. The neutrophil NLRC4 inflammasome selectively promotes IL-1beta maturation without pyroptosis during acute Salmonella challenge. Cell Reports. 2014; 8: 570-82.

15. Schroder K., Tschopp J. The inflammasomes. Cell. 2010; 140: $821-32$

16. Lovewell R.R. Patankar Y.R., Berwin B. Mechanisms of phagocytosis and host clearance of Pseudomonas aeruginosa American Journal of Physiology - Lung Cellular and Molecular Physiology. 2014; 306 (7): L591-L603. Published 2014 Apr 1. DOI: https://www.doi.org/10.1152/ajplung.00335.2013.

17. MariathasanS.,NewtonK.,MonackD.M.,VucicD.,FrenchD.M et al. Differential activation of the inflammasome by caspase-1 adaptors ASC and Ipaf. Nature. 2004; 430: 213-8.

18. Miao E.A., Ernst R.K., Dors M., Mao D.P., Aderem A. Pseudomonas aeruginosa activates caspase 1 through Ipaf. Pro. Natl Acad. Sci. USA. 2008; 105: 2562-7.

19. Зимина Е.М., Калошин А.А., Михайлова Н.А. Слитый рекомбинантный белок OprF-aTox-OprI Pseudomonas aeruginosa: получение и исследование иммунобиологических свойств. Цитокины и воспаление. 2017; 16 (4): 66-9.

\section{- References}

1. Rello J., Krenn C.G., Locker G., Pilger E., Madl C., et al. A randomized placebo-controlled phase II study of a Pseudomonas vaccine in ventilated ICU patients. Crit. Care. 2017; 21 (1): 22. DOI: https:// www.doi.org/10.1186/s13054-017-1601-9.

2. Mikhailova N.A., Kaloshin A.A., Zimina E.M., Soldatenkova A.V., Poddubikov A.V. Preclinical studies of a recombinant Pseudomonas aeruginosa vaccine. Journal of Microbiology, Epidemiology and Immunobiology. 2018; 6: 31-7. DOI: https://www.doi. org/10.36233/0372-9311-2018-6-31-37. (in Russian)

3. KaloshinA.A., SoldatenkovaA.V.,ZiminaE.M.,MikhaylovaN.A. Obtaining fused recombinant proteins OprF-AOprI, AOprF-AOprI and OprF-aTox-AOprI of Pseudomonas aeruginosa. Journal of Microbiology, Epidemiology and Immunobiology. 2017; 5: 32-8. DOI: https:// www.doi.org/10.36233/0372-9311-2017-5-32-38. (in Russian)

4. Khaitov R.M. Immunomodulators: myths and reality. Immunologiya. 2020; 41 (2): 101-6. DOI: https://www.doi org/10.33029/0206-4952-2020-41-2-101-106. (in Russian)

5. Ashmarin I.P., Vorob'ev A.A. Statistical methods in microbiological research. Leningad : Medgiz, 1962: 180 p. (in Russian)

6. Koval'chuk L.V.(eds.), Ignat'eva G.A. (eds.), Gankovskaya L.V. (eds.). Immunology. Workshop. Tutorial. Moscow : Geotar-Medicine. 2015: 176 p. (in Russian)

7. Rebrikov D.V. (eds.), Samatov G.A., Trofimov D.Yu., Semenov P.A., Savilova A.M., Kofiadi I.A., Abramov D.D. PCR «in real time». Moscow : BINOM. Knowledge Laboratory, 2009: 223 p. (in Russian)

8. Soldatenkova A.V., Akhmatova N.K., Mikhailova N.A. Influence of recombinant toxoid on-effectors of the immune response in mice. Immunologiya. 2012; 33 (5): 245-9. (in Russian)

9. Huang X., Du W., McClellan S.A., Barrett R.P., Hazlett L.D. TLR4 is required for host resistance in Pseudomonas aeruginosa keratitis. Invest. Ophthalmol. Vis. Sci. 2006; 47 (11): 4910-6. DOI: https:// www.doi.org/10.1167/iovs.06-0537.

10. Awasthi S., Singh B., Ramani V., Xie J., Kosanke S. TLR4 interacting SPA4 peptide improves host defense and alleviates tissue injury in a mouse model of Pseudomonas aeruginosa lung infection.
PLoS One. 2019; 14 (1). Published 2019 Jan 28. DOI: https://www. doi.org/10.1371/journal.pone.0210979.

11. Wu Y., Li D., Wang Y., Liu X., Zhang Y., et al. Beta-Defensin 2 and 3 Promote Bacterial Clearance of Pseudomonas aeruginosa by Inhibiting Macrophage Autophagy through Downregulation of Early Growth Response Gene-1 and c-FOS. Front. Immunol. 2018; 9: 211. DOI: https://www.doi.org/10.3389/fimmu.2018.00211.

12. Wu M., McClellan S.A., Barrett R.P., Zhang Y., Hazlett L.D. Beta-defensins 2 and 3 together promote resistance to Pseudomonas aeruginosa keratitis. J. Immunol. 2009; 183 (12): 8054-60. DOI https://www.doi.org/10.4049/jimmunol.0902140.

13. Pirozhkov S.V., Litvitskiy P.F. Inflammasome diseases. Immunologiya. 2018; 39 (2-3): 158-65. DOI: https://www.doi. org/10.18821/0206-4952-2018-39-2-3-158-165. (in Russian)

14. Chen K.W., Grob C.J., Sotomayor F.V., Stacey K.J., Tschopp J., et al. The neutrophil NLRC4 inflammasome selectively promotes IL1beta maturation without pyroptosis during acute Salmonella challenge. Cell Reports. 2014; 8: 570-82.

15. Schroder K., Tschopp J. The inflammasomes. Cell. 2010; 140 $821-32$

16. Lovewell R.R., Patankar Y.R., Berwin B. Mechanisms of phagocytosis and host clearance of Pseudomonas aeruginosa. American Journal of Physiology - Lung Cellular and Molecular Physiology. 2014; 306 (7): L591-L603. Published 2014. Apr 1. DOI: https://www. doi.org/10.1152/ajplung.00335.2013.

17. Mariathasan S., Newton K., Monack D.M., Vucic D., French D.M., et al. Differential activation of the inflammasome by caspase-1 adaptors ASC and Ipaf. Nature. 2004; 430: 213-8.

18. Miao E.A., Ernst R.K., Dors M., Mao D.P., Aderem A. Pseudomonas aeruginosa activates caspase 1 through Ipaf. Proc Natl Acad Sci USA. 2008; 105: 2562-7.

19. Zimina E.M., Kaloshin A.A., Mikhailova N.A. Pseudomonas aeruginosa OprF-aTox-OprI recombinant fusion protein: synthesis and study of immunobiological properties. Cytokines and Inflammation. 2017; 16 (4): 66-9. (in Russian) 


\section{Сведения об авторах}

Зимина Екатерина Максимовна - мл. науч. сотрудник лаборатории протективных антигенов ФГБНУ НИИВС им. И.И. Мечникова, Москва, Российская Федерация

E-mail: ziminka@yandex.ru

https://orcid.org/0000-0003-2167-8905

Калошин Алексей Алексеевич - канд. биол. наук, ведущ. науч сотр. лаборатории протективных антигенов ФГБНУ НИИВС им. И.И. Мечникова, Москва, Российская Федерация

E-mail: alex-k-1973@yandex.ru

https://orcid.org/0000-0001-8679-2421

Михайлова Наталья Александровна - д-р. мед. наук, проф., зав. лабораторией протективных антигенов ФГБНУ НИИВС им. И.И. Мечникова, Москва, Российская Федерация E-mail: n michailova@inbox.ru

https://orcid.org/0000-0002-6652-2093

Меркушова Екатерина Дмитриевна - ассистент каф. иммунологии медико-биологического факультета РНИМУ им. Н.И. Пирогова Минздрава России, Москва, Российская Федерация

E-mail: rina.karmin@outlook.com

https://orcid.org/0000-0003-0013-8651

Ганковская Людмила Викторовна - д-р мед. наук, проф., зав каф. иммунологии медико-биологического факультета РНИМУ им. Н.И. Пирогова Минздрава России, Москва, Российская Федерация

E-mail: lvgan@yandex.ru

https://orcid.org/0000-0003-1271-3078

\section{Authors' information}

Ekaterina M. Zimina - Junior Researcher of Laboratory of Protective Antigens, I. Mechnikov NIIVS, Moscow, Russian Federation

E-mail: ziminka@yandex.ru

https://orcid.org/0000-0003-2167-8905

Aleksey A. Kaloshin - PhD, Leader Researcher of Laboratory of Protective Antigens, I. Mechnikov NIIVS, Moscow, Russian Federation

E-mail: alex-k-1973@yandex.ru

https://orcid.org/0000-0001-8679-2421

Natal'ya A. Mikhailova - MD, PhD, Prof., Head of Laboratory of Protective Antigens, I. Mechnikov NIIVS, Moscow, Russian

Federation

E-mail: n michailova@inbox.ru

https://orcid.org/0000-0002-6652-2093

Ekaterina D. Merkushova - Assistant of the Dep. of Immunology, Med.-Biol. Faculty of N.I. Pirogov RNIMU, MOH of Russia, Moscow, Russian Federation

E-mail: rina.karmin@outlook.com

https://orcid.org/0000-0003-0013-8651

Lyudmila V. Gankovskaya - MD, PhD, Prof., Head of the Dep. of Immunology, Med.-Biol. Faculty of N.I. Pirogov RNIMU, MOH of Russia, Moscow, Russian Federation

E-mail: lvgan@yandex.ru

https://orcid.org/0000-0003-1271-3078 